Check for updates

Cite this: RSC Adv., 2019, 9, 9228

\title{
Fluorescence-tunable copper nanoclusters and their application in hexavalent chromium sensing $\dagger$
}

\begin{abstract}
Yu-Syuan Lin, Tai-Chia Chiu and Cho-Chun Hu D *
Generally, metal nanoclusters are synthesized using only a single ligand. Thus, the properties and applications of these nanomaterials are limited by the nature of the ligand used. In this study, we have developed a new synthetic strategy to prepare bi-ligand copper nanoclusters (Cu NCs). These bi-ligand $\mathrm{Cu}$ NCs are synthesized from copper ions, thiosalicylic acid, and cysteamine by a simple one-pot method, and they exhibit high quantum yields ( $>18.9 \%)$ and good photostability. Most interestingly, the fluorescence intensities and surface properties of the Cu NCs can be tailored by changing the ratio of the two ligands. Consequently, the bi-ligand Cu NCs show great promise as fluorescent probes. Accordingly, the $\mathrm{Cu}$ NCs were applied to the inner-filter-effect-based detection of hexavalent chromium in water. A wide linear range of $0.1-1000 \mu \mathrm{M}$ and a low detection limit (signal-to-noise ratio = 3) of $0.03 \mu \mathrm{M}$ was obtained. The recoveries for the real sample analysis were between 98.3 and $105.0 \%$ and the relative standard deviations were below $4.54 \%$, demonstrating the repeatability and practical utility of this assay.
\end{abstract}

Received 2nd February 2019 Accepted 15th March 2019

DOI: 10.1039/c9ra00916g

rsc.li/rsc-advances surface ligands strongly affect the light-emitting properties of the metal NCs. ${ }^{15}$

Many different ligands have been used to synthesize $\mathrm{Cu}$ NCs in recent years. For example, proteins that contain amine or thiol groups such as bovine serum albumin, human serum albumin, and soy protein have been used to engender the resulting $\mathrm{Cu}$ NCs with water solubility, and the $\mathrm{Cu}$ NCs produced were also highly fluorescent.6,16-26 However, these proteins are expensive and unstable in acidic environments, restricting the application of this type of $\mathrm{Cu}$ NCs. Cu NCs protected by small thiol molecules such as glutathione, cysteine, or penicillamine are very easy to prepare..$^{\mathbf{4 , 2 7 - 3 6}}$ However, most of these types of $\mathrm{Cu}$ NCs have low quantum yields (QYs), limiting their application.

All the above approaches employ a single ligand species to direct and cap the nascent NCs. Thus, we have found that $\mathrm{Cu}$ NCs capped using two different ligands are rarely studied and the effects of two ligands on $\mathrm{Cu}$ NC surfaces and fluorescence properties are relatively unexplored.

Chromium $(\mathrm{Cr}(\mathrm{vI}))$ is widely used in industrial processes such as metal smelting, leather tanning, electroplating, and dyeing. All these processes result in the release of large amounts of $\mathrm{Cr}(\mathrm{vI})$ into the environment, potentially contaminating drinking water and/or entering the food chain. $\mathrm{Cr}(\mathrm{vI})$ contamination is highly associated with allergic dermatitis, carcinogenesis, and mutagenesis in animals and humans. In addition to traditional instrumental analysis methods, several strategies have been developed for quantitative determination of $\mathrm{Cr}(\mathrm{vI})$ using nanomaterials based on phenomena such as the inner filter effect (IFE) ${ }^{37-42}$ electrochemical detection, ${ }^{\mathbf{4 3 , 4 4}}$ and absorbance detection. ${ }^{45-48}$ Of these, the IFE mechanism is the most
Department of Applied Science, National Taitung University, 369, Sec. 2, University Rd., Taitung, Taiwan, Republic of China.E-mail: cchu@nttu.edu.tw

$\dagger$ Electronic supplementary information (ESI) available: Additional information (Tables S1, S2, and Fig. S1-S5) is referenced in the text. See DOI: 10.1039/c9ra00916g 
widely exploited owing to its low detection limit and comparative freedom from matrix effects. ${ }^{49}$

Herein, we propose a new synthetic strategy to synthesis biligand $\mathrm{Cu} \mathrm{NCs}$ and a discussion of the relationship between the two ligands and the properties of the Cu NCs. We found that the fluorescence intensities and surface properties of the bi-ligand $\mathrm{Cu}$ NCs can be easily adjusted by changing the ratio of the two ligands. Furthermore, the blue emission of the bi-ligand $\mathrm{Cu}$ NCs is strongly quenched in the presence of $\mathrm{Cr}(\mathrm{vI})$ through the IFE mechanism, and this property allows our $\mathrm{Cu}$ NCs to be applied as a nanosensor for detecting $\mathrm{Cr}(\mathrm{VI})$.

\section{Experimental}

\subsection{Materials}

$\mathrm{Cu}\left(\mathrm{NO}_{3}\right)_{2} \cdot 5 \mathrm{H}_{2} \mathrm{O}$, cysteamine (CysA), and metal ions were received from Sigma-Aldrich (St. Louis, MO, USA). Thiosalicylic acid (TA) was received from Acros (Morris Plains, NJ, USA). Monobasic, dibasic, tribasic sodium salt of phosphate, phosphoric acid, and Tris were obtained from J.T. Baker (Phillipsburg, NJ, USA). Ultrapure water (18.25 $\mathrm{M} \Omega \mathrm{cm}^{-1}$ ) from a Milli-Q system of Millipore (Billerica, MA, USA) was used to prepare all aqueous and organic-aqueous solutions. All chemicals and solvents were analytical grade and used without further purification.

\subsection{Instrumentation}

UV-vis absorption spectra were performed on a Lambda EZ210 UV-vis spectrophotometer (Perkin Elmer, USA). Fluorescent spectra were performed on an F-7000 Fluorescence Spectrophotometer (Hitachi, Japan). Both of the excitation and emission slits were maintained at $5.0 \mathrm{~nm}$. The morphology and mean diameter of bi-ligand $\mathrm{Cu}$ NCs were performed on a transmission electron microscope (TEM, JEM-2100, Hitachi, Japan). X-ray photoelectron spectra were measured on an X-ray photoelectron spectroscopy (XPS, K-Alpha, Thermo, USA). Binding energy calibration was based on C $1 \mathrm{~s}$ at $284.6 \mathrm{eV}$. The stabilities and selectivity of bi-ligand $\mathrm{Cu}$ NCs were analyzed using an Infinite 200 PRO microplate reader (Tecan, Switzerland). The QY of bi-ligand $\mathrm{Cu}$ NCs were measured according to an established procedure. Quinine sulfate in $0.1 \mathrm{M} \mathrm{H}_{2} \mathrm{SO}_{4}$ (literature $\mathrm{QY}=0.54$ ) was chosen as a standard. Absolute values were calculated using the standard reference sample that has a fixed and known QY value. In order to minimize reabsorption effects, absorbencies in the $10 \mathrm{~mm}$ FL cuvette were kept under 0.1 at the excitation wavelength $(340 \mathrm{~nm})$.

\subsection{Preparation of bi-ligand $\mathrm{Cu}$ NCs}

The bi-ligand $\mathrm{Cu}$ NCs were prepared by the reported protocol with a new strategy. ${ }^{50}$ Aqueous $2 \mathrm{~mL}$ of $0.2 \mathrm{M} \mathrm{Cu}\left(\mathrm{NO}_{3}\right)_{2}$ was adding in to $8 \mathrm{~mL}$ of bi-ligand solutions prepared by $50 \mathrm{mM}$ TA (in EtOH) and $50 \mathrm{mM}$ CysA (see the detailed proportions in Table 1). The brown copper/thiol complexes were formed in the vial. A $10 \mathrm{~mL}$ of EtOH solutions were added in to the complexes solution to make the final concentration of EtOH was control at $40 \%$. Then the solutions were carried out by ultrasound for
$10 \mathrm{~min}$. Finally, the mixture was allowed to $40 \mathrm{~min}$ at $75^{\circ} \mathrm{C}$. The $\mathrm{Cu}$ NCs were purified by centrifugation $(3000 \mathrm{~g}, 10 \mathrm{~min})$ in order to remove the precipitate from the reaction solution.

The final solution was stored at $-20^{\circ} \mathrm{C}$ refrigerator until it was used. For simplicity, the concentrations of as-prepared biligand $\mathrm{Cu}$ NCs were denoted as $1 \times$. The as-prepared bi-ligand $\mathrm{Cu}$ NCs were denoted as $\mathrm{Cu}$ NC-0 to $\mathrm{Cu}$ NC-4 according to CysA amount were 0, 100, 200, 250 and $300 \mu \mathrm{mol}$, respectively.

\subsection{Determination of $\mathrm{Cr}(\mathrm{vr})$}

The Cu NC-2 prepared by TA-to-CysA molar ratio of $1: 1$ were used for the detection of $\mathrm{Cr}(\mathrm{vr})$. A $\mathrm{Cr}(\mathrm{vI})$ stock solution $(10 \mathrm{mM})$ and phosphate buffer solutions (100 mM, pH 5.0) were prepared. $1400 \mu \mathrm{L}$ ultrapure water, phosphate buffer $(200 \mu \mathrm{L}$, $100 \mathrm{mM}, \mathrm{pH} 5.0), 200 \mu \mathrm{L}$ of $0.1 \times \mathrm{Cu} \mathrm{NC}-2$ and $200 \mu \mathrm{L}$ of the $\mathrm{Cr}(\mathrm{vI})$ solution were added in to a quartz cuvette, sequentially. The final concentrations of $\mathrm{Cu} \mathrm{NC}-2$ in the mixtures were $0.01 \times$, while that for $\mathrm{Cr}(\mathrm{vI})$ were $0.1-1000 \mu \mathrm{M}$. The fluorescence spectra were recorded after the preparation. The excitation wavelength was setting at $355 \mathrm{~nm}$, and the PMT voltage was $600 \mathrm{~V}$.

\subsection{Detecting $\mathrm{Cr}(\mathrm{vI})$ in mineral water}

Mineral water samples received from local supermarket were centrifuged at $12000 \mathrm{rcf}$ for $30 \mathrm{~min}$ and filtrated through 0.22 $\mu \mathrm{m}$ membranes. $400 \mu \mathrm{L}$ of ultrapure water, $400 \mu \mathrm{L}$ of mineral water, phosphate buffer ( $200 \mu \mathrm{L}, 100 \mathrm{mM}, \mathrm{pH} 5.0), 200 \mu \mathrm{L}$ of $0.1 \times \mathrm{Cu} \mathrm{NC}$ and $1000 \mu \mathrm{L}$ of the $\mathrm{Cr}(\mathrm{vI})$ solution were added in to a quartz cuvette, sequentially. The fluorescence spectra were recorded after the preparation. The excitation wavelength was setting at $355 \mathrm{~nm}$, and the PMT voltage was $600 \mathrm{~V}$.

\section{Results and discussion}

\subsection{Synthesis and characterization of bi-ligand Cu NCs}

Thiol molecules are usually used as etching reagents for the formation of Cu NCs. ${ }^{51-55}$ However, this strategy requires long reaction times $(>4 \mathrm{~h})$ and a large amount of thiol (molar ratio: $\mathrm{R}$ $\mathrm{SH} / \mathrm{Cu}>5$ ). The synthesis of our bi-ligand $\mathrm{Cu}$ NCs is illustrated in Scheme 1. In this study, the bi-ligand $\mathrm{Cu}$ NCs were synthesized by heating copper ions in the presence of thiosalicylic acid (TA) and cysteamine (CysA) at different ratios. Our bi-ligand $\mathrm{Cu}$ NCs can be prepared using less reagent (molar ratio: $\mathrm{R}-\mathrm{SH} / \mathrm{Cu}=$ 1) and a shorter reaction time $(<2 \mathrm{~h})$ compared to those required

Table 1 The relationship between TA/CysA ratio and optical properties of bi-ligand $\mathrm{Cu} \mathrm{NCs}{ }^{a}$

\begin{tabular}{lllll}
\hline $\mathrm{Cu}$ NCs & $\begin{array}{l}\text { TA amount } \\
(\mu \mathrm{mol})\end{array}$ & $\begin{array}{l}\text { CysA amount } \\
(\mu \mathrm{mol})\end{array}$ & $\mathrm{Abs}_{340}$ & $\begin{array}{l}\text { Quantum yield } \\
(\%)\end{array}$ \\
\hline $\mathrm{Cu} \mathrm{NC}-0$ & 400 & 0 & 0.089 & 18.9 \\
$\mathrm{Cu} \mathrm{NC}-1$ & 300 & 100 & 0.071 & 25.4 \\
$\mathrm{Cu} \mathrm{NC}-2$ & 200 & 200 & 0.057 & 30.5 \\
$\mathrm{Cu} \mathrm{NC}-3$ & 150 & 250 & 0.042 & 31.5 \\
$\mathrm{Cu} \mathrm{NC}-4$ & 100 & 300 & 0.034 & 34.0
\end{tabular}

${ }^{a}$ The TA amount, CysA amount, absorbance at $340 \mathrm{~nm}$ and quantum yield of bi-ligand $\mathrm{Cu}$ NCs. 


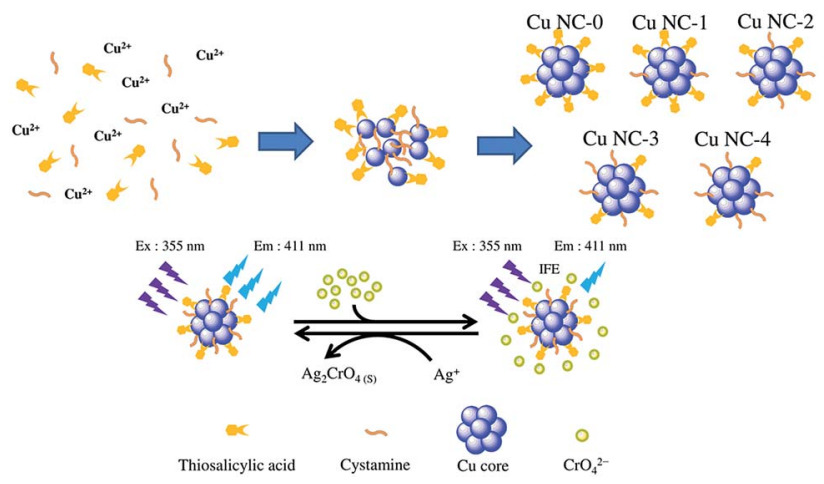

Scheme 1 Schematic illustration of the formation of bi-ligand Cu NC with different surface properties and IFE fluorescence determination of $\mathrm{Cr}(\mathrm{VI})$ using bi-ligand Cu NC. The bi-ligand Cu NCs were synthesized from copper ions, thiosalicylic acid (TA) and cysteamine (CysA). The fluorescent of bi-ligand $\mathrm{Cu}$ NCs can be quenched by $\mathrm{Cr}(\mathrm{VI})$ through an IFE then recovered by adding $\mathrm{Ag}^{+}$.

for the conventional method. This is due to the fact that both ligands act as reducing agents and protective agents during the reaction.

Upon fluorescence spectral measurement, the emission peaks of the different bi-ligand $\mathrm{Cu}$ NCs samples are observed at similar wavelengths. Fig. 1A shows the fluorescence excitation and emission spectrum of $\mathrm{Cu}$ NC-2. The maximum emission peak is observed at $411 \mathrm{~nm}$ upon excitation at $330 \mathrm{~nm}$, which is similar to that previously reported for TA-Cu NCs. ${ }^{50}$ The shape and size of the bi-ligand $\mathrm{Cu}$ NCs were examined using transmission electron microscopy (TEM), revealing that the morphologies of these bi-ligand $\mathrm{Cu}$ NCs are similar. From the TEM images and size distribution profiles shown in Fig. 1B, it can be seen that $\mathrm{Cu}$ NC-3 has an average particulate size of $c a$. $3.71 \pm 1.01 \mathrm{~nm}$. A small fraction of the $\mathrm{Cu} \mathrm{NC}-3$ has aggregated to form larger aggregates through hydrogen bonding and $\pi-\pi$
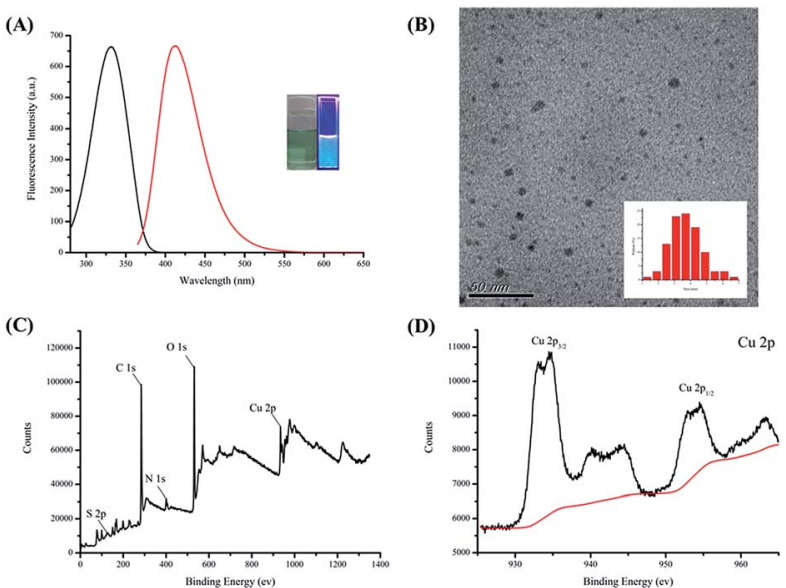

Fig. 1 Characterization of Cu NCs. (A) Excitation (black line) and emission spectra (red line) of $\mathrm{Cu} \mathrm{NC}$-2. The inset photograph is $\mathrm{Cu}$ NC-2 shown under daylight (left) and UV illumination (right). The excitation and emission wavelengths were $330 \mathrm{~nm}$ and $411 \mathrm{~nm}$, respectively. (B) The TEM images of the $\mathrm{CU} N \mathrm{NC}-3$. Inset (B): particle size distribution of $\mathrm{Cu} N \mathrm{NC}-3$. XPS survey $(\mathrm{C})$ and $\mathrm{Cu} 2 \mathrm{p}$ region (D) spectrum of the $\mathrm{Cu} \mathrm{NC}-2$. stacking. ${ }^{50}$ X-ray photoelectron spectroscopy analysis was conducted to determine the composition of the $\mathrm{Cu}$ NCs and the oxidation state of copper therein. It can be seen from Fig. 1C that signals from $\mathrm{C}, \mathrm{O}, \mathrm{N}, \mathrm{S}$, and $\mathrm{Cu}$ are detected. These results directly confirm the elemental composition of the bi-ligand $\mathrm{Cu}$ NCs. The two distinct peaks at 932.3 and $952.1 \mathrm{eV}$ in the $\mathrm{Cu} 2 \mathrm{p}$ spectrum are attributed to the $2 \mathrm{p} 3 / 2$ and $2 \mathrm{p} 1 / 2$ electrons of $\mathrm{Cu}(0)$, respectively (Fig. 1D). There is a small characteristic satellite peak around $942.0 \mathrm{eV}$ for $\mathrm{Cu} 2 \mathrm{p} 3 / 2$, which indicates the presence of some unreacted copper ions adsorbed on the surface of the bi-ligand $\mathrm{Cu}$ NCs.

Stability is a very important criterion for a nanosensor. Consequently, we investigated the salt tolerance and photostability of Cu NC-2 by measuring its fluorescence intensity. As shown in Fig. S1†, the fluorescence intensity changes little during 20 days storage at $-20^{\circ} \mathrm{C}$. Furthermore, Fig. S2A $\dagger$ shows that the fluorescence intensity of $\mathrm{Cu}$ NC-2 remains almost the same for $\mathrm{NaCl}$ concentrations up to $1 \mathrm{M}$. In Fig. $\mathrm{S} 2 \mathrm{~B} \dagger$, it can be seen that the fluorescence intensity does not change after $1 \mathrm{~h}$ of irradiation. These results indicate that $\mathrm{Cu}$ NC-2 has very good salt tolerance and light stability.

\subsection{Surface and fluorescence properties of bi-ligand $\mathrm{Cu}$ NCs}

The fluorescent of $\mathrm{Cu}$ NCs capped by TA can be attributed to inter-band and/or intra-band electronic transitions through LMCT. The formulas and properties of the five bi-ligand $\mathrm{Cu}$ NCs samples synthesized are shown in Table 1 . The absorbance of these bi-ligand $\mathrm{Cu}$ NCs increases gradually with increasing TA content, and their QY values increase with increasing CysA content (18.9-34.0\%).

To confirm the relationship between the spectral properties and synthetic formula, two plots have been drawn. As shown in Fig. 2A, the absorbance at $340 \mathrm{~nm}$ is linearly related to TA content, and Fig. 2B shows that QY is linearly related to CysA content. A higher absorbance means more energy is absorbed by the bi-ligand $\mathrm{Cu}$ NCs through LMCT (S-Cu), and a higher QY
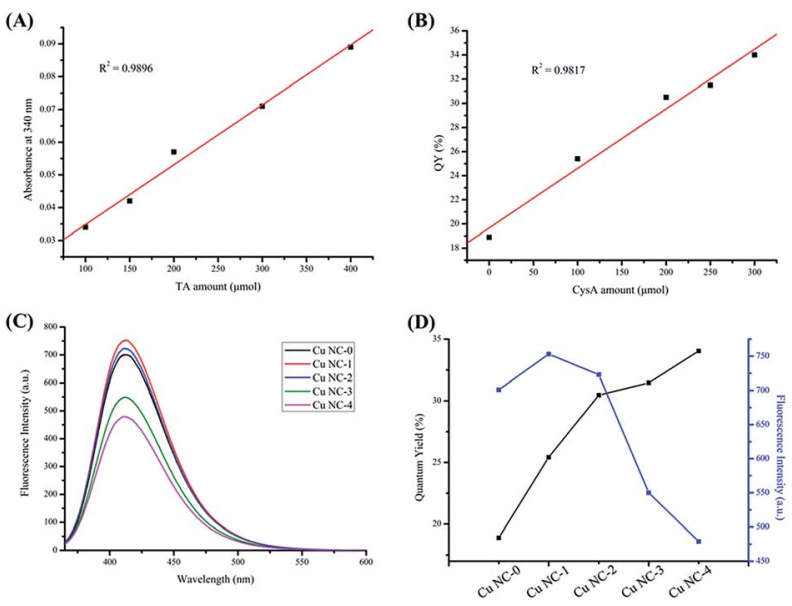

Fig. 2 Optical properties of bi-ligand Cu NCs. (A) Linear plot of the absorbance against TA amount in bi-ligand Cu NC. (B) Linear plot of the quantum yield against CysA amount in bi-ligand $\mathrm{Cu} N C$. (C) Emission spectra of bi-ligand Cu NC. (D) The fluorescence intensity and quantum yield of bi-ligand $\mathrm{Cu}$ NC. 
means more energy is released through the fluorescence process. Therefore, we can speculate that the TA absorbs excitation light, while CysA promotes electron transition between the ligand and metal. Specifically, the aromatic ring on TA absorbs energy from the excitation light and the CysA helps the excited electrons transfer to the copper through the inductive effect of the terminal amine, thereby increasing the QY. These results also support the conclusions drawn in a previous study. ${ }^{15}$ The emission spectra of the bi-ligand $\mathrm{Cu}$ NCs are shown in Fig. 2C. Hence, the ratio of these two ligands can be used to effectively regulate the fluorescence intensity of bi-ligand $\mathrm{Cu}$ NCs but also tune their surface properties. To develop a good fluorescence sensor, QY was plotted against the fluorescence intensity. As shown in Fig. 2D, the addition of CysA increases the QY, but reduces fluorescence intensity. Since Cu NC-2 exhibits both high QY and fluorescence intensity, Cu NC-2 was selected as a fluorescence sensor for all subsequent experiments.

The two ligands TA and CysA have amine and carboxyl groups, respectively. In a previous study, Au NPs prepared with a carboxyl protective agent were applied to the detection of melamine through hydrogen-bonding recognition interactions, ${ }^{56}$ which resulted in the aggregation of the Au NPs.

To prove that there are different amounts of amine groups on the surfaces of the different bi-ligand $\mathrm{Cu} \mathrm{NCs}$, various volumes of bi-ligand $\mathrm{Cu}$ NCs were mixed with $2 \mathrm{~mL}$ Au NPs (1.97 $\mathrm{mg} \mathrm{mL}^{-1}$ ). The results are shown in Fig. 3. The Au NPs begin aggregating when $17 \mu \mathrm{L} \mathrm{Cu} \mathrm{NC}-4$ is added. Furthermore, a significant color change is observed for the Au NPs when $25 \mu \mathrm{L}$ $\mathrm{Cu}$ NC-4 is added. Color changes are also observed when $30 \mu \mathrm{L}$ of $\mathrm{Cu}$ NC-3 is added, $40 \mu \mathrm{L}$ of Cu NC-2 is added, and $80 \mu \mathrm{L}$ of $\mathrm{Cu}$ NC-1 is added. However, no color change is observed upon the addition of $\mathrm{Cu}$ NC-0, even when $80 \mu \mathrm{L}$ is added.

$\mathrm{Cu}$ NC-4 has the highest CysA content, and thus less of it is required to cause $\mathrm{Au} \mathrm{NP}$ aggregation. $\mathrm{Cu} \mathrm{NC}-0$, which is synthesized using only TA, does not cause Au NP aggregation. The strong interaction between the Au NPs and the amine group of CysA on the surface of the bi-ligand $\mathrm{Cu}$ NCs plays an important role in Au NP aggregation. This is strong evidence to indicate that the bi-ligand $\mathrm{Cu}$ NCs samples have different amounts of amine groups on their surfaces. Thus, the surface

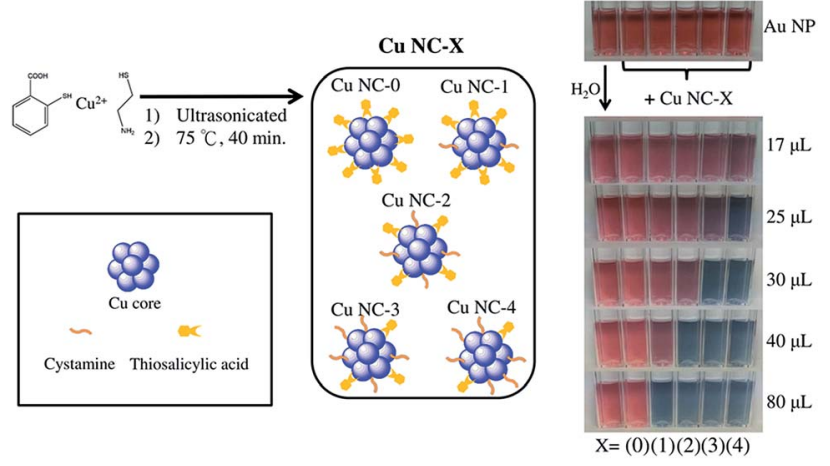

Fig. 3 Schematic illustration of the surface-tunable bi-ligand Cu NCs. The bi-ligand $\mathrm{Cu}$ NCs synthesized by different ratio of TA and CysA show different affinity to Au NPs. properties can be easily tuned by controlling the ratio of TA and CysA. The fluorescent of $\mathrm{Cu}$ NCs capped by TA can be attributed to inter-band and/or intra-band electronic transitions through LMCT. The formulas and properties of the five bi-ligand $\mathrm{Cu}$ NCs samples synthesized are shown in Table 1 . The absorbance of these bi-ligand $\mathrm{Cu}$ NCs increases gradually with increasing TA content, and their QY values increase with increasing CysA content (18.9-34.0\%).

\subsection{IFE determination of $\mathrm{Cr}(\mathrm{vI})$ using bi-ligand $\mathrm{Cu}$ NCs}

The excitation spectrum of $\mathrm{Cu}$ NC-2 and the absorption spectrum of $\mathrm{Cr}(\mathrm{vI})$ are shown in Fig. S3†. There is a large overlap between the two spectra, which indicates that the fluorescence of $\mathrm{Cu}$ NC-2 will be quenched owing to absorption by the $\mathrm{Cr}(\mathrm{vI})$ through the IFE mechanism. To confirm the IFE mechanism, silver ions were added into this system, as illustrated in Fig. 4. Upon the addition of $1 \mathrm{mM} \mathrm{Cr(v)}$, the fluorescence intensity of $\mathrm{Cu} \mathrm{NC}-2$ is initially quenched. However, the fluorescence is recovered by adding $0.2 \mathrm{M}$ silver ions to the solution. The fluorescence intensity of the solution increases after centrifugation to remove the precipitate. From these results, we could conclude that the fluorescence intensity of $\mathrm{Cu}$ NC-2 is quenched by $\mathrm{Cr}(\mathrm{vI})$ due to the IFE (red line) and recovered by silver ions owing to the IFE being turned off. It is thought that the fluorescence intensity does not recover completely because some of the $\mathrm{Cu}$ NC-2 is co-precipitated with the silver chromate. This specific fluorescence response of $\mathrm{Cu}$ NC-2 offers an attractive opportunity to develop a fluorescent sensor for $\mathrm{Cr}(\mathrm{vI})$ detection.

\subsection{Optimization for $\mathrm{Cr}(\mathrm{v})$ sensing}

Several experiments were conducted with the aim of optimizing the sensor efficacy. Fig. S4A† shows the fluorescence intensity changes for $\mathrm{Cu}$ NC-2 upon adding $1 \mathrm{mM} \mathrm{Cr(vI)}$ at different $\mathrm{pH}$. The maximum fluorescence changes at $\mathrm{pH} 5$, so $\mathrm{pH} 5$ was chosen for the assay conditions. Because the IFE is turned on by absorbing incident light, the excitation wavelength is very important for analytical performance. As shown in Fig. S4B†,

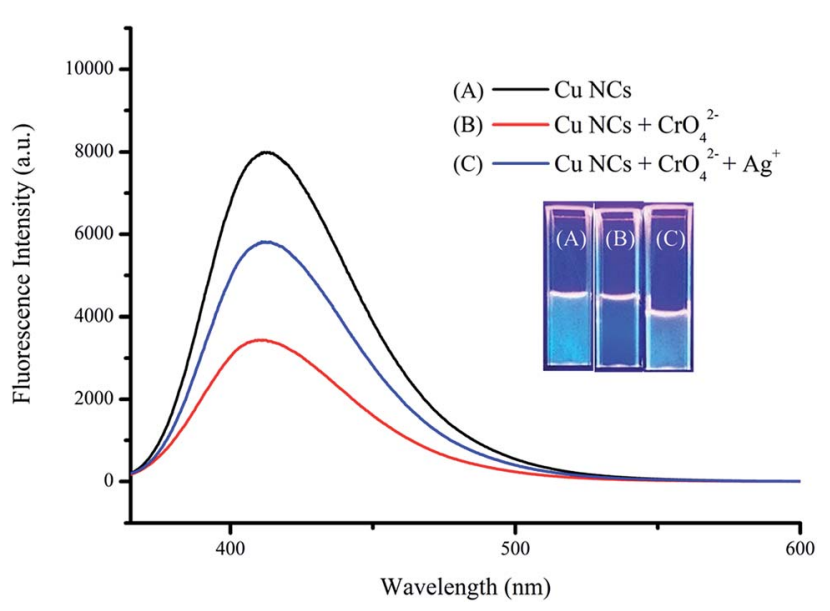

Fig. 4 Fluorescence of bi-ligand $\mathrm{Cu} \mathrm{NC-2}$ switches off and on. Fluorescence spectra of $\mathrm{Cu} \mathrm{NC}-2$ (A), Cu NC-2 containing $0.1 \mathrm{mM}$ of $\mathrm{Cr}(\mathrm{VI})(\mathrm{B})$ and $\mathrm{Cu} \mathrm{NC}-2$ containing $0.1 \mathrm{mM}$ of $\mathrm{Cr}(\mathrm{VI})$ and $20 \mathrm{mM}$ of $\mathrm{Ag}^{+}$ after centrifugation (C). 
the fluorescence intensity differences were invested under different excitation wavelengths from 330 to $370 \mathrm{~nm}$. To avoid the fluorescence intensity being too low to observe (thus negatively affecting the detection limit) an excitation wavelength of $355 \mathrm{~nm}$ was chosen for subsequent experiments.

Reaction time is also an important factor for the analytical assay. The time scan fluorescence spectra of $\mathrm{Cu}$ NC-2 with and without the addition of $1 \mathrm{mM} \mathrm{Cr(vI)}$ are shown in Fig. S5†. The fluorescence intensities of these two samples are very stable for $30 \mathrm{~min}$. This phenomenon indicates that our assay requires only a very short reaction time and the assay results are stable for at least $30 \mathrm{~min}$. Thus, the results confirm that our assay provides quick-response and stable sensing.

\subsection{Detection performance of $\mathrm{Cu}$ NC-2 in $\mathrm{Cr}(\mathrm{vI})$ sensing}

The performance of $\mathrm{Cu}$ NC-2 for detecting $\mathrm{Cr}(\mathrm{vI})$ based on fluorescence quenching through the IFE mechanism was carefully evaluated. Fig. 5A shows that the fluorescence intensity at $411 \mathrm{~nm}$ gradually decreases with increasing $\mathrm{Cr}(\mathrm{VI})$ concentration from 0.1 to $1000 \mu \mathrm{M}$. These results indicate that this fluorescence assay is very sensitive to changes in the $\mathrm{Cr}(\mathrm{vI})$ concentration. The experimental results presented in Fig. 5B demonstrate good linearity between the fluorescence intensity and the $\mathrm{Cr}(\mathrm{vI})$ concentration in the range $0.1-1000 \mu \mathrm{M}$ with
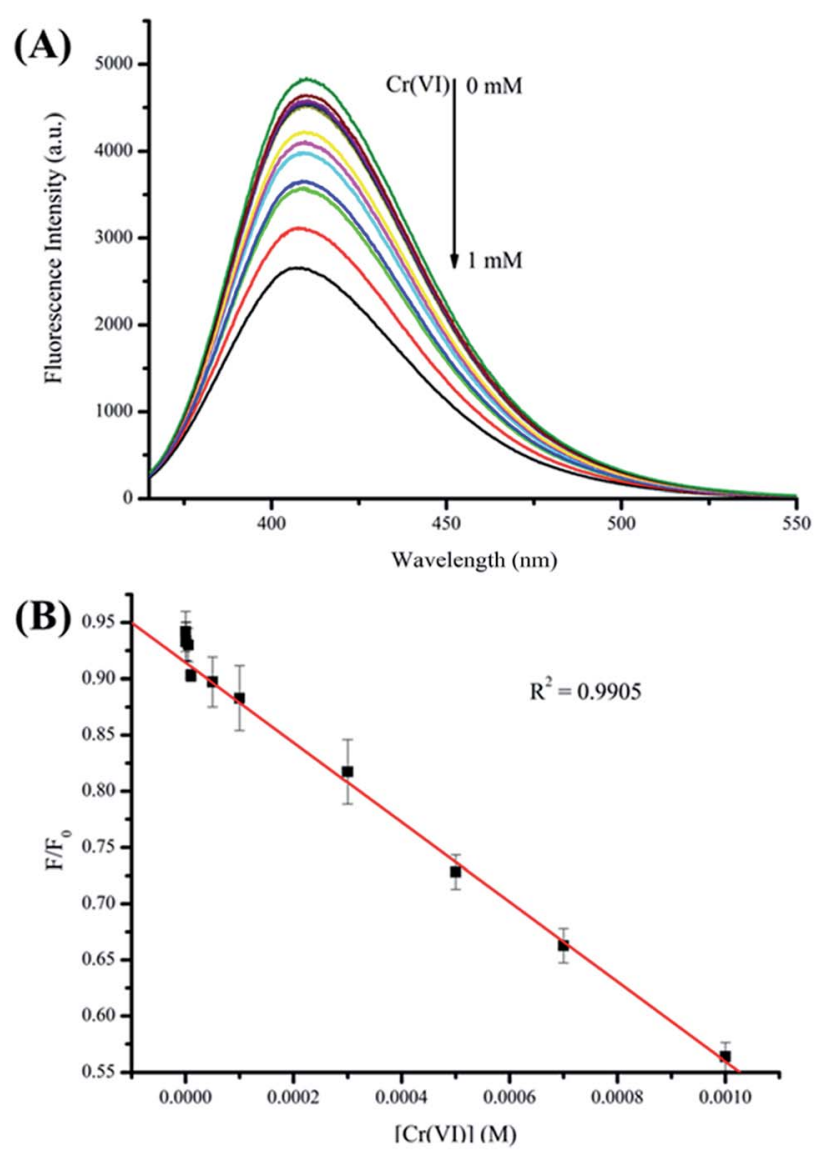

Fig. 5 Linear range of IFE detection of $\mathrm{Cr}(\mathrm{VI})$. (A) Detection of $\mathrm{Cr}(\mathrm{VI})$ in standard solutions using Cu NC-2. (B) Linear plot of relative fluorescence intensities of $\mathrm{Cu} \mathrm{NC-2}$ against $\mathrm{Cr}(\mathrm{vI})$ concentration. a low limit of detection of $0.03 \mu \mathrm{M}$ at a signal-to-noise ratio of 3 . The detection limit is substantially lower than the guideline limit stipulated by the World Health Organization $(0.96 \mu \mathrm{M}) .{ }^{57}$

Selectivity is another important criterion for sensors. Accordingly, interference and selectivity tests were performed. As shown in Fig. 6, it can be seen that most common metal ions that exist in the environment do not significantly interfere with our method. Only $\mathrm{Cr}(\mathrm{vI})$ causes an obvious change in fluorescence, and other metal ions like potassium, cobalt, calcium, magnesium, barium, mercury, copper, lithium, zinc, and nickel ions do not cause this change $(<7.5 \%)$. Thus, this method has excellent selectivity for the detection of $\mathrm{Cr}(\mathrm{vI})$.

To demonstrate that our assay can be used to detect $\mathrm{Cr}(\mathrm{vI})$ in

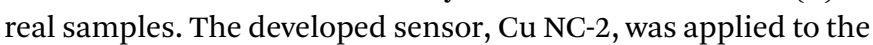
determination of $\mathrm{Cr}(\mathrm{vI})$ in a mineral water samples obtained from a local supermarket. The water samples were analyzed after spiking with $\mathrm{Cr}(\mathrm{vI})$ at 10,14 , and $20 \mu \mathrm{M}$. The recoveries obtained are from 98.3 to $105.0 \%$ and the relative standard deviations are less than $4.54 \%(n=3)$. These data are shown in Table S1 $\uparrow$. Compared with other sensors reported in the literature (Table S2 $\dagger$ ), our sensor is more sensitive than most
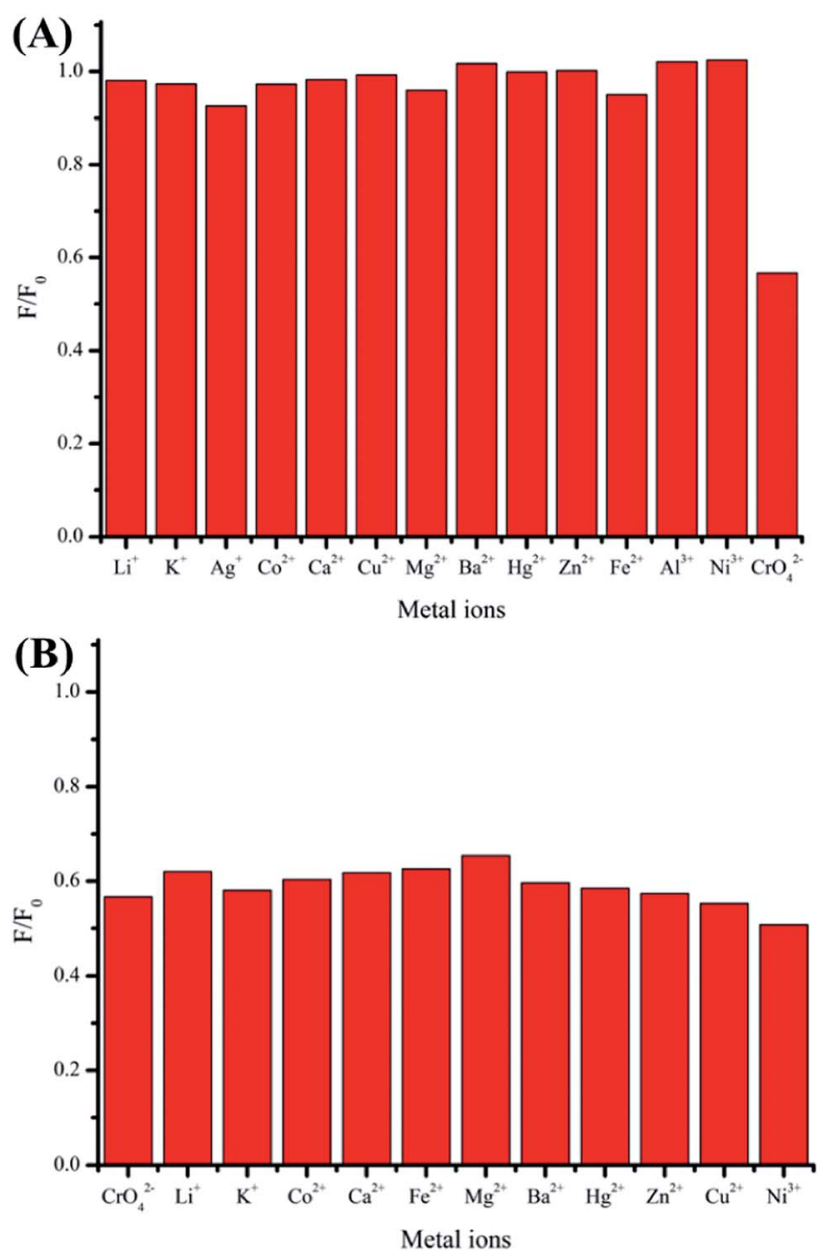

Fig. 6 Selectivity and interference of IFE detection of $\mathrm{Cr}(\mathrm{VI})$. Relative emission intensities $\left(F / F_{0}\right)$ of as-prepared $\mathrm{Cu} N \mathrm{~N}-2$ after the addition of $10^{-4} \mathrm{M}$ of different metal ions (A) in the presence of $10^{-4} \mathrm{M}$ of $\mathrm{Cr}(\mathrm{VI})(\mathrm{B})$. Mixtures were prepared in phosphate buffer $(0.1 \mathrm{M}, \mathrm{pH}$ 5.0). 
nanosensors reported. Thus, as well as presenting a high QY and simple preparation, our assay has a short response time and can be used for real water sample sensing.

\section{Conclusions}

In summary, a novel bi-ligand $\mathrm{Cu}$ NC nanosensor was prepared and its fluorescence properties were investigated, leading to the development of a simple, stable, selective, and sensitive method for detecting $\operatorname{Cr}(\mathrm{VI})$ in water samples. Using this bi-ligand strategy, the synthesized Cu NCs not only exhibited high QYs but also tunable surface and fluorescence properties. After optimization, the QY of the bi-ligand $\mathrm{Cu}$ NCs reached $34.0 \%$, and they were used for IFE-based $\mathrm{Cr}(\mathrm{VI})$ detection. We anticipate that more customized $\mathrm{Cu}$ NCs may be developed by this multiple-ligand synthetic strategy, and our research provides a simple and effective example.

\section{Conflicts of interest}

There are no conflicts to declare.

\section{Acknowledgements}

This work was supported by the NTTU and Ministry of Science and Technology, Taiwan (MOST 106-2113-M-143-003).

\section{References}

1 S. Choi, R. M. Dickson and J. Yu, Chem. Soc. Rev., 2012, 41, 1867-1891.

2 R. W. Murray, Chem. Rev., 2008, 108, 2688-2720.

3 X. Yuan, Z. T. Luo, Y. Yu, Q. F. Yao and J. P. Xie, Chem.-Asian J., 2013, 8, 858-871.

4 T. Zhou, Q. Yao, T. Zhao and X. Chen, Talanta, 2015, 141, 8085.

5 X. Yang, Y. Feng, S. Zhu, Y. Luo, Y. Zhuo and Y. Dou, Anal. Chim. Acta, 2014, 847, 49-54.

6 P. Ni, Y. Sun, H. Dai, J. Hu, S. Jiang, Y. Wang and Z. Li, Biosens. Bioelectron., 2015, 63, 47-52.

7 Y. Zhong, Q. Wang, Y. He, Y. Ge and G. Song, Sens. Actuators, $B, 2015,209,147-153$.

8 X. Le Guével, C. Spies, N. Daum, G. Jung and M. Schneider, Nano Res., 2012, 5, 379-387.

9 J. Wang, J. Ye, H. Jiang, S. Gao, W. Ge, Y. Chen, C. Liu, C. Amatore and X. Wang, RSC Adv., 2014, 4, 37790-37795.

10 J. Wang, G. Zhang, Q. Li, H. Jiang, C. Liu, C. Amatore and X. Wang, Sci. Rep., 2013, 3, 1157.

11 Y. Wang, J. T. Chen and X. P. Yan, Anal. Chem., 2013, 85, 2529-2535.

12 M. De, P. S. Ghosh and V. M. Rotello, Adv. Mater., 2008, 20, 4225-4241.

13 J. R. Bhamore, B. Deshmukh, V. Haran, S. Jha, R. K. Singhal, N. Lenka, K. Kumar and Z. V. K. Murthy, New J. Chem., 2018, 42, 1510-1520.
14 J. R. Bhamore, S. Jha, A. I. Mungara, R. K. Singhal, D. Sonkeshariya and S. K. Kailasa, Biosens. Bioelectron., 2016, 80, 243-248.

15 Z. Wu and R. Jin, Nano Lett., 2010, 10, 2568-2573.

16 H. Chen, L. Lin, H. Li, J. Li and J. M. Lin, ACS Nano, 2015, 9, 2173-2183.

17 D. Q. Feng, W. Zhu, G. Liu and W. Wang, RSC Adv., 2016, 6, 96729-96734.

18 C. Zhang, L. Zeng, X. Zhu, C. Yu, X. Zuo, X. Xiao and J. Nan, Anal. Methods, 2013, 5, 2203-2208.

19 L. Jin, Z. Zhang, A. Tang, C. Li and Y. Shen, Biosens. Bioelectron., 2016, 79, 108-113.

20 H. Li, C. Wang, P. Gai, T. Hou, L. Ge and F. Li, RSC Adv., 2016, 6, 76679-76683.

21 Y. Qiao, T. Xu, Y. Zhang, C. Zhang, L. Shi, G. Zhang, S. Shuang and C. Dong, Sens. Actuators, B, 2015, 220, 1064-1069.

22 A. Singh, T. Rai and D. Panda, $R S C A d v$., 2016, 6, 5553955545.

23 X. Q. Liao, R. Y. Li, Z. J. Li, X. L. Sun, Z. P. Wang and J. K. Liu, New J. Chem., 2015, 39, 5240-5248.

24 S. Xu, M. Deng, Y. Sui, Y. Zhang and F. Chen, RSC Adv., 2014, 4, 44644-44649.

25 J. K. Yang, H. Kang, H. Lee, A. Jo, S. Jeong, S. J. Jeon, H. I. Kim, H. Y. Lee, D. H. Jeong, J. H. Kim and Y. S. Lee, ACS Appl. Mater. Interfaces, 2014, 6, 12541-12549.

26 G. Zhang, T. Xu, H. Du, Y. Qiao, X. Guo, L. Shi, Y. Zhang, S. Shuang, C. Dong and H. Ma, J. Mater. Chem. C, 2016, 4, 3540-3545.

27 P. C. Chen, Y. C. Li, J. Y. Ma, J. Y. Huang, C. F. Chen and H. T. Chang, Sci. Rep., 2016, 6, 24882.

28 H. Huang, H. Li, J. J. Feng, H. Feng, A. J. Wang and Z. Qian, Sens. Actuators, B, 2017, 241, 292-297.

29 Y. Huang, H. Feng, W. Liu, Y. Zhou, C. Tang, H. Ao, M. Zhao, G. Chen, J. Chen and Z. Qian, Anal. Chem., 2016, 88, 1157511583.

30 Y. Huang, W. Liu, H. Feng, Y. Ye, C. Tang, H. Ao, M. Zhao, G. Chen, J. Chen and Z. Qian, Anal. Chem., 2016, 88, 74297434.

31 X. Jia, X. Yang, J. Li, D. Li and E. Wang, Chem. Commun., 2014, 50, 237-239.

32 J. Y. Ma, P. C. Chen and H. T. Chang, Nanotechnology, 2014, 25, 195502.

33 L. Kong, X. Chu, W. Liu, Y. Yao, P. Zhu and X. Ling, New J. Chem., 2016, 40, 4744-4750.

34 D. Li, Z. Chen, Z. Wan, T. Yang, H. Wang and X. Mei, RSC Adv., 2016, 6, 34090-34095.

35 S. M. Lin, S. Geng, N. Li, N. B. Li and H. Q. Luo, Talanta, 2016, 151, 106-113.

36 R. Y. Li, H. Y. Wang, X. Y. Zhou, X. Q. Liao, X. L. Sun and Z. J. Li, New J. Chem., 2016, 40, 732-739.

37 F. Cai, X. Liu, S. Liu, H. Liu and Y. Huang, RSC Adv., 2014, 4, 52016-52022.

38 M. Cui, G. Song, C. Wang and Q. Song, Microchim. Acta, 2015, 182, 1371-1377.

39 H. L. Tao, M. Z. Xu, Q. J. Zhang, X. H. Zhang, S. H. Li, F. X. Zhong, C. Sun and X. F. Liao, Anal. Methods, 2013, 5, 5961-5968. 
40 M. Rong, L. Lin, X. Song, Y. Wang, Y. Zhong, J. Yan, Y. Feng, X. Zeng and X. Chen, Biosens. Bioelectron., 2015, 68, 210-217.

41 Z. Zhang, C. Sha, A. Liu, Z. Zhang and D. Xu, J. Fluoresc., 2015, 25, 335-340.

42 A. Zheng, J. Chen, G. Wu, G. Wu, Y. G. Zhang and H. Wei, Spectrochim. Acta, Part A, 2009, 74, 265-270.

43 W. Jin, G. Wu and A. Chen, Analyst, 2014, 139, 235-241.

44 R. Ouyang, S. A. Bragg, J. Q. Chambers and Z. L. Xue, Anal. Chim. Acta, 2012, 722, 1-7.

45 W. Chen, F. Cao, W. Zheng, Y. Tian, Y. Xianyu, P. Xu, W. Zhang, Z. Wang, K. Deng and X. Jiang, Nanoscale, 2015, 7, 2042-2049.

46 J. F. Guo, D. Q. Huo, M. Yang, C. J. Hou, J. J. Li, H. B. Fa, H. B. Luo and P. Yang, Talanta, 2016, 161, 819-825.

47 F. M. Li, J. M. Liu, X. X. Wang, L. P. Lin, W. L. Cai, X. Lin, Y. N. Zeng, Z. M. Li and S. Q. Lin, Sens. Actuators, B, 2011, 155, 817-822.

48 X. Wu, Y. Xu, Y. Dong, X. Jiang and N. Zhu, Anal. Methods, 2013, 5, 560-565.
49 J. Li, X. Li, X. Shi, X. He, W. Wei, N. Ma and H. Chen, ACS Appl. Mater. Interfaces, 2013, 5, 9798-9802.

50 Y. J. Lin, P. C. Chen, Z. Yuan, J. Y. Ma and H. T. Chang, Chem. Commun., 2015, 51, 11983-11986.

51 Y. S. Borghei, M. Hosseini, M. R. Ganjali and S. Hosseinkhani, Sens. Actuators, B, 2017, 248, 133-139.

52 R. Ghosh, U. Goswami, S. S. Ghosh and A. Paul, ACS Appl. Mater. Interfaces, 2015, 7, 209-222.

53 R. Gui, J. Sun, X. Cao, Y. Wang and H. Jin, RSC Adv., 2014, 4, 29083-29088.

54 C. Wang, H. Cheng, Y. Huang, Z. Xu, H. Lin and C. Zhang, Analyst, 2015, 140, 5634-5639.

55 S. Yang, X. Sun and Y. Chen, Mater. Lett., 2017, 194, 5-8.

56 K. Ai, Y. Liu and L. Lu, J. Am. Chem. Soc., 2009, 131, 94969497.

57 S. H. Frisbie, E. J. Mitchell, H. Dustin, D. M. Maynard and B. Sarkar, Environ. Health Perspect., 2012, 120, 775-778. 